\section{Physician associates in primary care}

I am delighted to see this subject taking a prominent position in discussions on human resources for the NHS and in particular in primary care. It was back in 1981 that Ian FM Saint-Yves and I wrote about this subject. ${ }^{1-3}$ However at that time the reaction from the profession was mainly derided and considered unnecessary.

I hope the observational studies continue to show GPs how effective this additional resource will be to support primary care now and in the future.

\section{John Stephenson,}

Retired GP, Brighton.

E-mail: brightondrjohname.com

\section{REFERENCES}

1. Stephenson JP. Rethinking the primary health care team. Primary Care 1981; 9: 5-6.

2. Saint-Yves IFM. Need general practitioner be patient's first contact with health service? Lancet 1980; 316(8194): 578-580.

3. Saint-Yves IFM. The training of paramedics for primary health care. J R Soc Health 1983; 103(4): 135-137.

DOI: 10.3399/bjgp15X685201

\section{Self-monitoring of blood glucose in type 2 diabetes}

If the purpose of this research ${ }^{1}$ is to create cost-cutting opportunities for the NHS then I can still not applaud it. Diabetes UK's position statement on self-monitoring of blood glucose (SMBG) for adults with type 2 diabetes states 'The Department of Health, the pharmaceutical industry and commissioners of services should together review the cost of testing strips and together negotiate a reduction in cost to the NHS ${ }^{2}$ This point would, in my opinion, offer a more realistic and balanced approach to financial savings than this article.

Writing as a type 1 diabetic I would like to highlight my concerns with this study. First, how can the researchers know what effectiveness their study had on the health of those participating if they did not continually measure it? If there is a necessity for SMBG in those at risk of hypoglycaemia, what about those at risk of hyperglycaemia; for example, the majority of type 2 diabetics? Did the removal of SMBG from those participating have an adverse effect on blood glucose levels and lead to an increased rate of complications and cost of treatment?

Then, the authors state that patients report that use of SMBG can be associated with feelings of blame or failure, and disappointment when clinicians are disinterested in readings. Does this mean SMBG does not work? What about the patients who exercise good control through a knowledge of what impact the food they eat has on their blood glucose levels? This is only possible through SMBG. Feelings of pride, control and motivation when the individual is successful and when the clinician is interested are equally important.

This study sought to offer a cost reduction in the NHS budget, not to implement NICE guidance. There is no concern for the benefits to the patient. Withdrawing the availability of SMBG will not address the issue of poor implementation and, until such time as there is proper implementation, the effectiveness of SMBG for any diabetic will not be properly recognised.

The key to diabetes treatment is in empowering the patient; in making the patient take ownership and control of their condition. To do that requires the appropriate tools.

Stuart Whellans,

\section{Engineer.}

E-mail: swhellans77abtinternet.com

\section{REFERENCES}

1. Robson J, Smithers H, Chowdhury T. Reduction in self-monitoring of blood glucose in type 2 diabetes: an observational controlled study in east London. Br J Gen Pract 2015; DOI: 10.3399/bjgp15X684421.

2. Diabetes UK. Self monitoring of blood glucose (SMBG) for adults with type 2 diabetes. Position statement. https://www.diabetes.org.uk/ Documents/Position\%20statements/DiabetesUK-position-statement-SMBG-Type2-0413.pdf laccessed 6 May 2015).

DOI: 10.3399/bjgp15X685213

\section{Authors' response}

We thank Stuart Whellans for his comments on our study on reduction of self-monitoring of blood glucose. ' We can reassure him that the study was entirely concerned with people with type 2 diabetes who were not on insulin and who are at low risk of hypoglycaemia. Our study does not deal with people on insulin who require self-testing.

All people with type 2 diabetes are recommended to have regular blood checks using HbA1c. For many of these people not on insulin with low risk of hypoglycaemia, this is a sufficient measure of glycaemic control and self-testing offers no added benefit. Self-testing in this group of people does not reduce hypoglycaemia nor does it improve diet or outcomes. Many patients regard self-monitoring as a task that reduces their quality of life; disposal of sharps can be hazardous, and self-monitoring has been associated with infection. As well as patient wellbeing and safety, cost is a further consideration.

People with type 2 diabetes not on insulin at low risk of hypoglycaemia should be reviewed on an individual case-by-case basis. Most patients are pleased and relieved to have a twice-yearly HbA1c check rather than frequent self-tests that result in reduced quality of life without tangible benefit.

John Robson,

GP and Reader, Centre for Primary Care and Public Health, Queen Mary University of London.

E-mail: j.robsonaqmul.ac.uk

Tahseen Chowdhury, Consultant Physician, Barts Health NHS Trust, London.

\section{REFERENCE}

1. Whellans S. Self-monitoring of blood glucose in type 2 diabetes. Br J Gen Pract 2015; DOI: 10.3399/ bjgp15X685213.

DOI: 10.3399/bjgp15X685225

\section{Correction}

In the March 2015 article by Martins T, et al. Ethnic differences in patients' preferences for prostate cancer investigation: a vignette-based survey in primary care. Br J Gen Pract 2015; DOI: 10.3399/ bjgp15X683965, Figure 1 stated: 'Missing data on ethnicity, $n=128$; Aged <40 years $n=147$ ', whereas this should have been: 'Declined participation =128; Aged $<40$ years $n=19$ '. We apologise for this error. The online version has been corrected. DOI: 10.3399/ bjgp15X685081. 